\title{
A Hybrid Method for Vendor Selection using Neural Network
}

\author{
Jitendra Kumar \\ Department of Mechanical \\ Engineering, MNNIT, Allahabad, India
}

\author{
Nirjhar Roy \\ Department of Mechanical \\ Engineering, MNNIT, Allahabad, India
}

\begin{abstract}
Problem of vendor evaluation and selection has always been viewed as the most important responsibility of purchasing department and for such reason, received a great deal of attention from practitioners and researchers. This solution has always been a complex process as various criteria, known and half known are involved in making a decision. This work attempts to develop a rule based model, to evaluate the performance of vendors, supplying components and raw materials to a multinational organization engaged in designing, manufacturing and delivering a range of products covering various stages of electric power transmission and distribution system. To select the vendors, there is a need to rank all the potential vendors according to a performance measure because in this industry almost all items are outsourced from vendors and input material cost constitute almost $80 \%$ cost of the product. For such reason any organization is required to select suitable vendors who can supply input materials and components to the organization as per the need timely with right specification and requisite quantity.

This paper presents a hybrid model using analytic hierarchy process (AHP) and neural networks (NNs) theory to assess vendor performance. The model consists of two modules: Module 1 applies AHP using pair wise comparison of criteria for all vendors, In the process the importance of the criteria is also obtained using an iterative algorithm. Module 2 utilizes the results of AHP into NNs model for vendor selection. The results yield the best vendor and appropriate score to compare the performance of each vendor. Selection of alternative vendors also can be carried out by using the historical data. Validation of the entire developed algorithm has been carried out separately.
\end{abstract}

\section{Keywords}

Supply chain, Optimization, Vendor selection, Networking, method of AHP and neural network theory.

\section{INTRODUCTION}

Supply chain (SC) vendor evaluation is a very important operational decision, involving selection of vendors in various realistic situations with myriad constraints. Globalization has led to the opportunities for many, to utilize resources from around the world. This, phenomenon may introduce additional decisionmaking considerations. Further vendor selection decisions are complicated by the fact that various possible criteria, some of them are partly known may shadow the decision-making process. Proper identification of vendors is important for increasing the efficiency of service and manufacturing organizations. The purchased department focuses more on "A" types of items for administrative purposes. Most of the time the purchasing department uses some tools for decision making to evaluate vendors. The variable market condition also necessitates that in any organization specific SC models must be developed and applied.

This paper considers the case of a manufacturing organisation which provides comprehensive electrical solutions for utilities and electrointensive industries engaged in (a) transmission, distribution and power generation, (b) railways, (c) industrial buildings and mining and metal industries. The manufacturing organisation, under consideration has multi-plants and is located in several countries. Vendors are distributed evenly in those countries and the organisation attempts to purchase raw materials and components from local suppliers.

Some of the customers of this organisation also require certain components (or raw materials) to be purchased directly from their selected vendor. Price may not be the criteria for these purchases. For these cases the manufacturer does not have the freedom to select the vendors themselves on the basis on cost or time parameters. No systematic procedure or mathematical model is applicable for such situations. The manufactured items are power transformers of various sizes and specifications. It may be noted that a customer may opt for any type of transformers as per their need.

\section{LITERATURE SURVEY}

Many research methodologies of vendor analysis have been reported and applied. For an extensive review of literatures please refer [9]. Also the research works in [22] [10] and [11] are very informative and contain reviews of previous researches. A new grey-based approach to deal with the supplier selection problem is presented in [14].

The first published work [7] in the direction of vendor selection is meaningful for research purposes. In this article the terms vendor and supplier are often mean same and used interchangeably. A dogmatic framework of supplier selection situations that not necessarily coincides with supplier selection processes found in practice in [8] and [12] which offer a purchaser a manageable number of typical, different supplier selection situations with associated ways of carrying out and organizing the supplier selection process.

Traditional methods of vendors' evaluation in the early 80 s are mainly based on buyer's experience. The qualitative methodology have utilized in [20] and [28] for performance evaluation of vendors. Qualitative methods may include tools for visualizing and analysing the decision-maker's perception of a problem situation and tools for brainstorming about possible (alternative) solutions.

In the domain of quantitative techniques, a series of research papers [4-6] had addressed to solve cost based optimization 
problems. Research work as presented in [26] is improvised over the previous paper as in [25] and developed as a multi objective programming model to fix number of suppliers/vendors in SC. Though the list of such researches is wide and the techniques range from linear programming to highly complex mathematical modelling which are often found to be NP hard. Thus practical and realistic models are more preferred for vendor selection by industrial organisations. The quantitative techniques cause significant problems in considering qualitative factors. The models which can combine subjective and quantitative criteria are more useful for practical application. Hybrid systems had been implemented to solve vendor selection method [23] which had also attempted to quantify the attributes like quality, cost and delivery parameters so as to make the selection of vendors more justified. Previous work as in [22] is the original concept which has culminated in [23].

For dealing with multi-level criteria for vendor selection, analytic hierarchy process (AHP) had widely been in use for solving such problems. A web-based AHP system had been developed in [1] and is based on AHP, as utilised in [19] to evaluate the suppliers of casting with respect to 18 different criteria. A five-step AHP based model [16] had been proposed to aid decision makers in rating and selecting suppliers with respect to nine evaluating criteria. An AHP methodology [21] based on a combined AHP and a genetic algorithm (GA) also developed as cited in [24]. However the GA in vendor selection is not much utilised in realistic problems.

Artificial neural network (ANN), an evolutionary optimisation based algorithm had been developed in [13], [18], and [17]. ANN based algorithms are claimed to be helpful for practical industrial applications especially for dynamic situations. A neural network has one or more input nodes and one or more neurons. Some neuron's outputs are the output of the network. The network is defined by the neurons and their connections and weights. All neurons are organized into layers; the sequence of layers defines the order in which the activations are computed.

In many realistic applications, organizations have utilized their own methods as illustrated in [2] and [15]. The experience of the management staff is often seen to generate acceptable results in decision making process by using rules of thumb and is not reported in literature. Dependencies on use of theoretical models are avoided mostly by such industrial organizations. An intelligent supplier relationship management system (ISRMS) using hybrid case based reasoning (CBR) and artificial neural networks (ANNs) techniques to select and benchmark potential suppliers is discussed in [3]. A hybrid model is presented in [27] using data envelopment analysis (DEA), decision trees (DT) and neural networks (NNs) to assess supplier performance which yield a favorable classification and prediction accuracy rate.

This paper presents a hybrid model using analytic hierarchy process (AHP) and neural networks (NNs) to assess vendor performance. The model consists of two modules: Module 1 applies AHP and pair wise comparison of criteria and vendors with respect to each criterion to obtain the weight of each criteria and vendors. Module 2 utilizes the results (weights) of AHP into NNs model for vendor selection. Our results yield the best vendor and appropriate score to know the performance of each vendor. Moreover, to our knowledge, there is no work to analyze the vendor selection problem by jointly using AHP and NNs approaches. It is very attractive to use DEA and NNs approaches to develop an integrated model, which involves the advantages of both AHP and NNs.

Section 3 provides the description of the model, developed in this paper. Section 4 and 5 illustrates the AHP/NN results and conclude on the specific utility of the model.

\section{MODELS DESCRIPTION}

The model consists of two modules; module 1 applies AHP to calculate the weight of each criterion identified for vendor evaluation. Module 2 utilizes the weight of each criterion for neural network based model to select the best vendor and find alternate vendors on the basis of performance (score) of each vendor.

\subsection{AHP vendor selection model}

A method of analytic hierarchy process (AHP) for the fixation of vendors is described hereunder.

Step 1: Structure of the decision problem can be shown in a hierarchy of goal (best vendor), criteria and alternatives (vendors). The criteria here are taken as an illustrative example as quality of the product expressed in percentage of rejected parts, delay time, unit cost of the input and quality of service of the vendors. The relative importance given for these criteria may be considered as $\mathrm{w} 1, \mathrm{w} 2, \mathrm{w} 3$ and $\mathrm{w} 4$. These values of relative importance " $\mathrm{w}_{\mathrm{i}} \mathrm{s}$ " are not known by the manufacturers and the decision criteria of the customers may react in different ways. Fig. 1 shows the diagrammatic representation of the AHP model as applied to vendor selection.

Step 2: Compare the alternatives based on the criteria, adapted from a common scale [19].

Step 3: Synthesize the comparisons to obtain the priorities of the alternatives with respect to each criteria and the weights of each criteria with respect to the goal. Local priorities are then multiplied by the weight of the respective criteria and the results are summed up to produce the overall priority of each alternative (vendor).

\subsection{Neural network model}

The concept of neural networks started in the late-1800s and traditionally, the term neural network had been used to refer to a network or circuit of biological neurons. The modern usage of the term often refers to artificial neural networks, which are composed of artificial neurons or nodes.

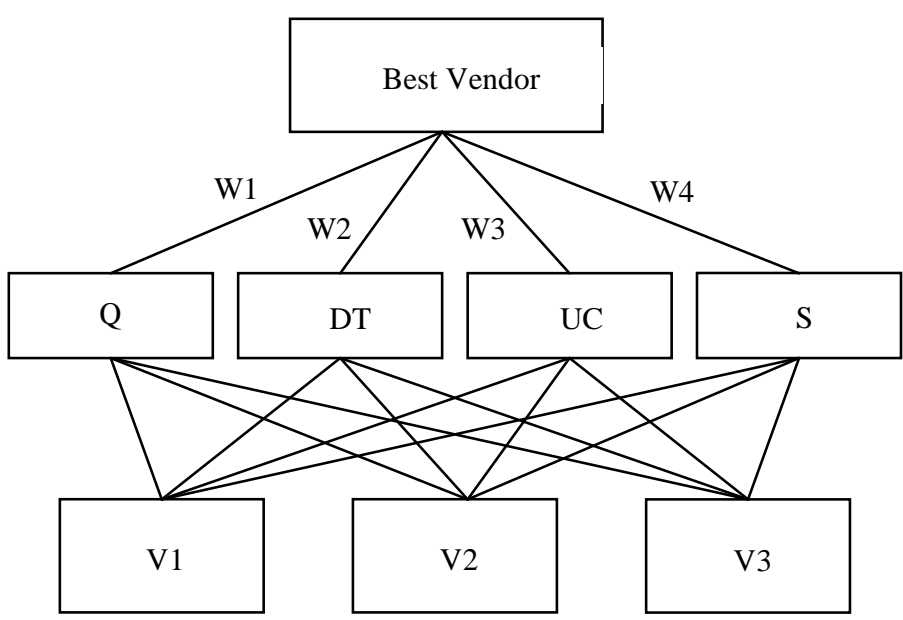

Fig. 1. A AHP model for vendor selection of a transformer industry 
Neural networks provide a new way for feature extraction (using hidden layers) and classification (e.g. multilayer perception). The perceptron is essentially a linear classifier for classifying data specified by parameters and an output function. Its parameters are adapted with an ad-hoc rule similar to stochastic steepest gradient descent. Because the inner product is a linear operator in the input space, the perceptron can only perfectly classify a set of data for which different classes are linearly separable in the input space, while it often fails completely for non-separable data.

The cognitron (1975) was an early multilayered neural network with a training algorithm. Networks can propagate information in one direction only, or they can bounce back and forth until selfactivation at a node occurs and the network settles on a final state. The ability for bi-directional flow of inputs between neurons/nodes was produced with the Hopfield's network (1982), and specialization of these node layers for specific purposes was introduced through the first hybrid network.

The rediscovery of the back propagation algorithm was probably the main reason behind the repopularisation of neural networks after the publication of "Learning Internal Representations by Error Propagation" in 1986 (Though back propagation itself dates from 1974). The original network utilized multiple layers of weight-sum units with a sigmoid function or logistic function such as used in logistic regression. There are three major learning paradigms, each corresponding to a particular abstract learning task. These are supervised learning, unsupervised learning and reinforcement learning. Usually any given type of network architecture can be employed in any of those tasks.

\subsubsection{Supervised learning}

In supervised learning, a set of example pairs (x, y), x $\varepsilon \mathrm{X}, \mathrm{y} \varepsilon \mathrm{Y}$ is inputed. The aim is to find a function $f$ in the allowed class of functions that matches the examples. In other words, the aim is intended to how the mapping may be implied by the data and the cost function is related to the mismatch between the referred mapping and the data.

\subsubsection{Unsupervised learning}

In unsupervised learning with a given input data $x$, sigmoid function $\left[1 /\left(1+\mathrm{e}^{-\alpha(\text { (xiwi) }}\right)\right]$ is to be minimized which can be any function of $x$ is related to the network's output, $y=f(w, x)$, where $\mathrm{w}$ is the matrix of all weight vectors. This method of learning is adopted in this study.

\subsubsection{Reinforcement learning}

In reinforcement learning, data $x$ is usually not known and as such cannot be inputed. However it can be generated by an agent's interactions with the environment. At each point in time $t$, the agent performs an action $y_{t}$ and the environment generates an observation $x_{t}$ and an instantaneous cost $c_{t}$, according to some (usually unknown) dynamics.

\subsection{Hybrid conceptual model}

The conceptual model for vendor selection using AHP and, NNs concept is shown in Fig. 2. As mentioned before, the hybrid model using analytic hierarchy process (AHP) and neural networks (NNs) theory can truly assess vendor performance. As mentioned before the technique, used here consists of two modules. Module 1 applies AHP and pair wise comparison of criteria and vendors with respect to each criterion to obtain the weight. Module 2 utilizes the results (weights) of AHP into NNs model for vendor selection. The results yield the best vendor and appropriate weights to know the performance of each vendor. The main algorithm is shown below.

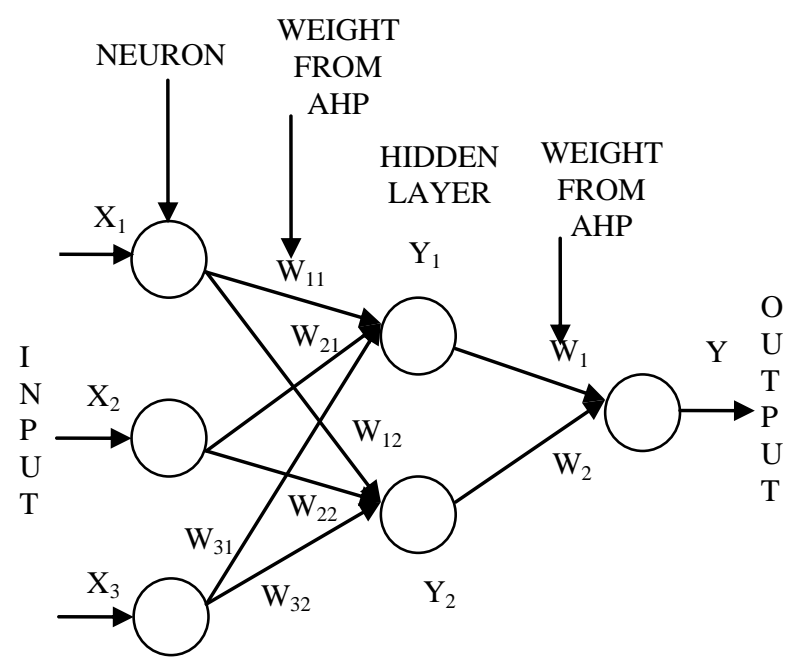

Fig. 2. The hybrid model for vendor selection

\subsubsection{Algorithm}

The algorithm is described below:

Input the no. of criteria decided.

Input the no. vendors.

Define the scale for criteria using Saaty's common scale.

Enter the data of each vendor.

Generate a matrix for comparison of each criteria of goal.

Create a matrix for the calculation of weights on objective by using the following formula:

Weight of given criteria $=$ Value of given criteria / Sum of column value

Generate the comparison matrix for vendor with respect to given criteria.

Create next matrix for the calculation of weight of vendor with respect to criteria by using the following formula:

Weight of given vendor wrt criteria $=$ Value of given vendor / Sum of column value

Repeat the steps for vendors until the criteria $\mathrm{i}=0$

Create a matrix for hidden layer by using the following formula:

Output value for hidden layer $\mathrm{Yc}_{\mathrm{i}}=1 /\left(1+\mathrm{e}^{-\alpha(\Sigma \mathrm{XXWci})}\right)$

Create a matrix for output layer by using following formula:

Value for output layer $\mathrm{Yv}_{\mathrm{i}}=1 /\left(1+\mathrm{e}^{-\alpha(\Sigma \mathrm{YciWvi})}\right)$

$\mathrm{Yv}_{\mathrm{i}}=$ Total score of vendor

Select the vendor of max. score from the above matrix for the best vendor.

Stop. 


\section{NUMERICAL ILLUSTRATION}

\subsection{Data}

The data is derived from a large, multinational, transformer manufacturing company, which is a global leader in design, production, and marketing of power and distribution transformers systems. Table- 1 shows the data of the quality (Q), delay times (DT), unit cost (UC) and services(S) of seven vendors.

Table 1. Vendor data

\begin{tabular}{|l|c|c|c|c|}
\hline V & $\begin{array}{l}\text { Q (\% } \\
\text { R.P.) }\end{array}$ & $\begin{array}{l}\text { DT } \\
\text { (Days) }\end{array}$ & $\begin{array}{l}\text { UC } \\
\text { (Rs.) }\end{array}$ & S \\
\hline V1 & 1 & 5 & $1.85 \mathrm{LAC} / \mathrm{T}$ & $\mathrm{AV}$ \\
\hline V2 & 1 & 4 & $2.68 \mathrm{LAC} / \mathrm{T}$ & $\mathrm{G}$ \\
\hline V3 & 2 & 10 & $2.31 \mathrm{LAC} / \mathrm{T}$ & $\mathrm{O}$ \\
\hline V4 & 5 & 12 & $2.55 \mathrm{LAC} / \mathrm{T}$ & $\mathrm{G}$ \\
\hline V5 & 3 & 11 & $2.01 \mathrm{LAC} / \mathrm{T}$ & $\mathrm{VG}$ \\
\hline V6 & 2 & 18 & $2.71 \mathrm{LAC} / \mathrm{T}$ & $\mathrm{O}$ \\
\hline V7 & 0 & 15 & $2.85 \mathrm{LAC} / \mathrm{T}$ & $\mathrm{AV}$ \\
\hline
\end{tabular}

O-Outstanding, VG-Very good, G-Good,, AV-Average, P-Poor

\subsection{Implementation and calculation}

The above steps can be illustrated with the data shown in Table-1. Scaling of each criteria is carried out with respect to one selected and considered as the most important criteria (say: quality).

Quality is somewhat more important than delay time-3 Quality is much more important than unit cost-5 Quality is very much more important than service-7 Delay time is somewhat more important than unit cost -3 Delay time is much more important than service-5

Unit cost is somewhat more important than service-3

Consider a data sheet of seven vendors of a component. Table-1 shows the quality, delay times unit cost and services of vendors. The method as shown on the left hand side of the page is used. The tables 2 and 3 are showing the pair wise comparison of criteria and weight on objective with respect to goal (preference on quality).The table 4 and 5 are showing pair wise comparison of vendors with respect to quality and its weight from vendor data.

In this industry for quality maximum rejection parts is $8 \%$ and total scale is divided from $1 \%$ to $8 \%$ (i.e. for difference of $0 \%-1$, $1 \%-2,2 \%-3,3 \%-4,4 \%-5,5 \%-6,6 \%-7,7 \%-8,8 \%-9)$. For delay times maximum days is 15 and these days are divided into scale of 1 to 9 (i.e. for difference of $0=1,1-2=2,3=3,4-5=4,6=5,7-8=6$, $9=7,10-11=8,12-15=9)$.For unit cost the total difference of cost is $1.00 \mathrm{Lac} / \mathrm{T}$ (i.e. $2.85-1.85=1.00$ ) and difference of each component cost has been taken and scale is used for these differences between 1-9 (i.e. for difference of $0=1$, up to. $125=2$, $.126-.250=3, \quad .251-.375=4, \quad .376-.500=5, \quad .501-.625=6$, .626$.750=7, .751-.875=8, .876-1.00=9)$. For service scale is divided between $P$ to $O$ (Poor to Outstanding i.e. $P=2, A=3, G=5, V G=7$, $\mathrm{O}=9$ ) by 1 to 9 (i.e. for difference of $1-2=2,3=3,4-5=5,6-7=7,8$ $9=9)$.
All computations are obtained by pair wise comparison of vendors with respect to delay times, unit cost and service and arranged in table 6. Now we will use all weight for criteria and vendors in hybrid model for vendor selection (figure 2).

Table 2. Performance on criteria

\begin{tabular}{|l|c|c|c|c|}
\hline CR & Q & DT & UC & S \\
\hline Q & 1 & 3 & 5 & 7 \\
\hline DT & $1 / 3$ & 1 & 3 & 5 \\
\hline UC & $1 / 5$ & $1 / 3$ & 1 & 3 \\
\hline S & $1 / 7$ & $1 / 5$ & $1 / 3$ & 1 \\
\hline
\end{tabular}

Table 3. Weight on objectives

\begin{tabular}{|c|c|c|l|l|l|}
\hline CR & Q & DT & UC & S & AV \\
\hline Q & .598 & .662 & .536 & .438 & .559 \\
\hline DT & .197 & .221 & .322 & .313 & .262 \\
\hline UC & .119 & .073 & .107 & .188 & .122 \\
\hline S & .085 & .044 & .035 & .063 & .057 \\
\hline
\end{tabular}

Table 4. Relatiive matrix of vendors with respect to quality

\begin{tabular}{|l|l|l|l|l|l|l|l|}
\hline & V1 & V2 & V3 & V4 & V5 & V6 & V7 \\
\hline V1 & 1 & 1 & 2 & 5 & 3 & 2 & $1 / 2$ \\
\hline V2 & 1 & 1 & 2 & 5 & 3 & 2 & $1 / 2$ \\
\hline V3 & $1 / 2$ & $1 / 2$ & 1 & 4 & 2 & 1 & $1 / 3$ \\
\hline V4 & $1 / 5$ & $1 / 5$ & $1 / 4$ & 1 & $1 / 3$ & $1 / 4$ & $1 / 6$ \\
\hline V5 & $1 / 3$ & $1 / 3$ & $1 / 2$ & 3 & 1 & $1 / 2$ & $1 / 4$ \\
\hline V6 & $1 / 2$ & $1 / 2$ & 1 & 4 & 2 & 1 & $1 / 3$ \\
\hline V7 & 2 & 2 & 3 & 6 & 4 & 3 & 1 \\
\hline
\end{tabular}

Table 5. Weight on quality

\begin{tabular}{|c|c|c|c|c|c|c|c|c|}
\hline & V1 & V2 & V3 & V4 & V5 & V6 & V7 & AV \\
\hline V1 & .18 & .18 & .21 & .18 & .20 & .21 & .16 & .19 \\
\hline V2 & .18 & .18 & .21 & .18 & .20 & .21 & .16 & .19 \\
\hline V3 & .09 & .09 & .10 & .14 & .13 & .10 & .11 & .11 \\
\hline V4 & .04 & .04 & .03 & .04 & .02 & .03 & .05 & .03 \\
\hline V5 & .06 & .06 & .05 & .11 & .07 & .05 & .08 & .07 \\
\hline V6 & .09 & .09 & .10 & .14 & .13 & .10 & .11 & .11 \\
\hline V7 & .36 & .36 & .31 & .21 & .26 & .31 & .32 & .30 \\
\hline & & & & & & & & $\sum=1$ \\
\hline
\end{tabular}


Table 6. Weight Matrix of Vendors

\begin{tabular}{|l|l|l|l|l|}
\hline $\mathbf{V}$ & \multicolumn{1}{|c|}{$\mathbf{Q}$} & $\mathbf{D T}$ & $\mathbf{U C}$ & $\mathbf{S}$ \\
\hline V1 & .19 & .30 & .41 & .03 \\
\hline V2 & .19 & .40 & .05 & .07 \\
\hline V3 & .11 & .10 & .14 & .32 \\
\hline V4 & .03 & .06 & .08 & .07 \\
\hline V5 & .07 & .06 & .26 & .13 \\
\hline V6 & .11 & .03 & .04 & .33 \\
\hline V7 & .30 & .05 & .02 & .05 \\
\hline
\end{tabular}

Table 7. Output values for hidden layer

\begin{tabular}{|l|l|l|l|l|}
\hline Criteria & Weight & $\begin{array}{c}\text { Input } \\
\text { value } \\
\mathbf{X i}\end{array}$ & $\mathbf{\Sigma X i W}_{\mathbf{C i}}$ & $\begin{array}{c}\text { Output value } \\
\text { for hidden } \\
\text { layer } \\
\text { Yci }\end{array}$ \\
\hline Q & .559 & & .760 & .681 \\
\hline DT & .262 & & .463 & .614 \\
\cline { 1 - 1 } UC & .122 & \multirow{2}{*}{.143} & .322 & .580 \\
\cline { 1 - 1 } & & .057 & .257 & .564 \\
\hline
\end{tabular}

$\Sigma \mathrm{XiW}_{\mathrm{Cl}}=.143 \mathrm{x} .559+.143 \mathrm{x} .559+.143 x .559+.143 x .559+.143 x .559$ $+.143 \times .559+.143 \times .559+1 \times .2=.760$

Let input value for all bias neuron $=1$

Let weight for all bias neuron $=0.2$

$\mathrm{Xi}=$ Input value for input layer $=1 / 7=.143$

$\mathrm{W}_{\mathrm{Ci}}=$ Weight of criteria

$\mathrm{Yc}_{\mathrm{i}}=$ Output value for hidden layer $=1 /\left(1+\mathrm{e}^{-\alpha(\Sigma \mathrm{XiWci})}\right)=$ Input value for output layer

$\alpha=1$

$\mathrm{Yc}_{1}=.681$

Table 8. Matrix for output layer

\begin{tabular}{|c|l|l|l|l|l|l|}
\hline $\mathbf{V}$ & $\begin{array}{c}\mathbf{Y c}_{\mathbf{1}}= \\
\mathbf{6 8 1}\end{array}$ & $\begin{array}{c}\mathbf{Y c}_{\mathbf{2}}= \\
\mathbf{. 6 1 4}\end{array}$ & $\begin{array}{c}\mathbf{Y c}_{\mathbf{3}}= \\
\mathbf{. 5 8 0}\end{array}$ & $\begin{array}{c}\mathbf{Y c}_{\mathbf{4}}= \\
\mathbf{. 5 6 4}\end{array}$ & $\begin{array}{c}\mathbf{\Sigma} \mathbf{Y c}_{\mathbf{i}} \mathbf{W}_{\mathbf{V}} \\
\mathbf{i}\end{array}$ & $\mathbf{Y v i}$ \\
\hline V1 & .19 & .30 & .41 & .03 & .769 & .683 \\
\hline V2 & .19 & .40 & .05 & .07 & .639 & .655 \\
\hline V3 & .11 & .10 & .14 & .32 & .598 & .645 \\
\hline V4 & .03 & .06 & .08 & .07 & .344 & .585 \\
\hline V5 & .07 & .06 & .26 & .13 & .518 & .627 \\
\hline V6 & .11 & .03 & .04 & .33 & .499 & .622 \\
\hline V7 & .30 & .05 & .02 & .05 & .471 & .616 \\
\hline
\end{tabular}

$\Sigma \mathrm{Yc}_{\mathrm{i}} \mathrm{W}_{\mathrm{V} 1}=.681 \times .19+.614 x .30+.58 \mathrm{x} .41+.564 \times .03+1 \mathrm{x} .2=.76$

9

$\mathrm{W}_{\mathrm{V} 1}=$ Weight of vendor wrt criteria

$\mathrm{Yv}_{\mathrm{i}}=$ Value for output layer $=1 /\left(1+\mathrm{e}^{-\alpha(\Sigma \mathrm{YciWvi})}\right)=$ Total score of vendor

$\mathrm{Yv}_{1}=0.683$

\subsection{Validation of proposed model \& Vendor selection}

In our example we have taken data of seven vendors of a component with some important criteria. Here we are trying to take the advantages of AHP and NNs theory. The main role of AHP is to calculate weight of each criteria and vendor for neural network. Input value for all neurons are same and it depends upon no. of vendors. Input value and weight (assumed) for all bias neurons are same. The bias accounts only for the degree of fitting the given data, but not for the level of generalization. A bias term can be treated as a connection weight from a special unit with a constant, nonzero activation value. The term "bias" is usually used with respect to a "bias unit" with a constant value of one. Not all authors follow this distinction. Regardless of the terminology, biases are added or subtracted has no effect on the performance of the network. Output value for hidden layer is calculated in table 7 which is the input values for output layer.

In table 8 total score for all vendors are calculated and we can see that vendor 1 is the best vendor because it has maximum score (.683) in comparison to all other vendors. For validation of this method through vendor data (table 1) that vendor 1 has less rejection parts, less delay time, less unit cost and average service against other vendors, so vendor 1 is the best. In this paper quality has much effect on total score of vendor because quality is main objective for selection of vendor.

\section{DISCUSSION}

It is important to note that supply chains (SC), can be viewed as a network of vendors, manufacturers, distributors, and retailers. The efficiency of the network is dictated mainly by the characteristics of vendors and also is influenced by mode of transportation, information flow, and financial infrastructure. The ability to represent a complex but realistic supply chain of any organization by using any model is often difficult if the organization supplies customized products to its customers. The preferences of vendors from customers side create further problems. It is very attractive to use AHP and NNs approaches to develop an integrated model, which involves the advantages of both.

\section{CONCLUSIONS}

This paper has developed a hybrid vendor selection model using analytic hierarchy process (AHP) and neural networks (NNs). The model enables us to deal with the complexity and criteria embedded in the vendor selection problem. The model consists of two modules: Module 1 applies AHP and pair wise comparison of criteria and vendors with respect to each criterion to obtain the weight of each criteria and vendors. Module 2 utilizes the results of AHP into NNs model for vendor selection. Our results yield the best vendor and appropriate score to know the performance of each vendor. However, the results are meaningful in that this study provides the hybrid to integrate AHP and NNs techniques and demonstrate its application to vendor selection problem. In addition, the results of this study provide on the way for selecting the appropriate prediction method for any type of dataset problem. A promising area of future research would be in applying this approach to compare the performance of other vendor selection methods. 


\section{REFERENCES}

[1] Akarte, M. M., Surendra, N.V., Ravi, B., and Rangaraj N. 2001. Web based casting supplier evaluation using analytical hierarchy process. Journal of the Operational Research Society, Vol. 52, no. 5, pp. 511-522.

[2] Boer, L. De, Van der Wegen, L., and Telgen, J. 1998. Outranking methods in support of supplier selection. European Journal of Purchasing and Supply Management, vol. 4, no. 2/3, pp.109-118.

[3] Choya, K. L., Leea, W. B., and Lo, V. 2003. Design of an intelligent supplier relationship management system: a hybrid case based neural network approach. Expert Systems with Applications, vol. 24, pp. 225-237.

[4] Degraeve, Z. and Roodhooft, F. 1998. Determining sourcing strategies: a decision model based on activity and cost driver information. Journal of the Operational Research Society, vol. 49 , no. 8, pp. 81-789.

[5] Degraeve, Z. and Roodhooft, F. 1999. Improving the efficiency of the purchasing process using total cost of ownership information: the case of heating electrodes at Cockerill Sambre S. A. European Journal of Operational Research, vol.112, no. 1, pp. 42-53.

[6] Degraeve, Z. and Roodhooft, F. 2000. A mathematical programming approach for procurement using activity based costing. Journal of Business Finance and Accounting, vol. 27, no. (1-2), pp. 69-98.

[7] Dickson, G. W. 1966. A analysis of vendor selection systems and decisions. J. Purch, vol. 2, pp. 5-17.

[8] Faris, C.W., Robinson, P.J., and Wind, Y. 1967. Industrial Buying and Creative Marketing. Allyn \& Bacon, Boston.

[9] Ho, W., Xu, X., and Dey, P. K. 2010. Multi - criteria decision making approaches for supplier evaluation and selection: A literature review. European Journal of Operational Research, vol. 202, pp.16-24.

[10] Huang, S. H. and Keskar, H. 2007. Comprehensive and configurable metrics for supplier selection. International Journal of Production Economics, vol. 105, no. 2, pp. 510 523.

[11] Humphreys, P., Huang, G., Cadden, T., and McIvor, R. 2007. Integrating design metrics within the early supplier selection process. Journal of Purchasing \& Supply Management, vol. 13, pp. 42-52.

[12] Kraljic, P. 1983. Purchasing must become supply management. Harvard Business Review, vol. 61, no. 5, pp. 109-117.

[13] Larson, G. B. 1995. An ANN pruning algorithm based approach to vendor selection. Journal of Systems Management (USA), vol. 46, no. 5, pp. 56-60.

[14] Li, Guo-Dong, Yamaguchi, D., and Nagai, M. 2007. A greybased decision-making approach to the supplier selection Problem. Mathematical and Computer Modeling, vol. 46, pp. 573-581.

[15] Mohammad Ebrahim, R., Razmi, J., and Haleh, H. 2009. Scatter search algorithm for supplier selection and order lot sizing under multiple price discount environment. Advances in Engineering Software, vol. 40, pp. 766-776.

[16] Muralidharan, C., Anantharaman, N., and Deshmukh, S. G. 2002. A multi-criteria group- decision making model for supplier rating. Journal of Supply Chain Management, vol. 38 , no. 4, pp. 22-33.

[17] Ozdemir, D., and Temur, G. T. 2009. DEA ANN approach in supplier evaluation system. World Academy of Science, Engineering and Technology, 54.

[18] Quin, L. 2009. An ANN pruning algorithm based approach to vendor selection. Kybernetes, vol. 38, 3-4, pp. 314-320.

[19] Saaty, T. L. 1980. The analytic hierarchy process. New York: McGraw-Hill.

[20] Timmerman, E. 1986. An approach to vendor performance evaluation. Journal of Purchasing and Supply Management, vol. 1, pp. 27-32.

[21] Venkata Rao, R. 2007. Supplier selection in a supply chain using analytic hierarchy process and genetic algorithm methods. International Journal of Services and Operations Management, vol. 3, no. 3, pp. 355-369.

[22] Verma, R. and Pullman, M. E. 1998. An analysis of supplier selection process. Omega, Int. J. Mgmt. Sci., vol. 26, no. 6, pp. 739-750.

[23] Wang, G., Huang, S. H., and Dismukes, J. P. 2004. Productdriven supply chain selection using integrated multi-criteria decision-making methodology. International Journal of production Economics, vol. 91, no. 1, pp. 1-15,

[24] Wang, H. S., and Che, Z. H. 2007. An integrated model for supplier selection decisions in configuration changes. Expert Systems with Applications, vol. 32, pp. 1132-1140.

[25] Weber, C. A., Current, J. R., and Desai, A. 1998. Noncooperative negotiation strategies for vendor selection. European Journal of Operational Research, vol. 108, pp. 208-223.

[26] Weber, C. A., Current, J. R., and Desai, A. 2000. An optimization approach to determining the number of vendors to employ. Supply Chain Management: An International Journal, vol. 5, no. 2, pp. 90-98.

[27] Wu, D. 2009. Supplier selection: A hybrid model using DEA, decision tree and neural network. Expert Systems with Applications, vol. 36, pp. 9105-9112.

[28] Zenz, G. 1981. Purchasing and the Management of Materials. Wiley, New York. 